\title{
The Effect of Interlayer on Water Cut Rise in a Bottom Water Reservoir
}

\author{
Yunpeng Hu $\mathbb{D},{ }^{1}$ Xiaoling Zhang $\mathbb{D},{ }^{2}$ Wei Ding $\mathbb{D}^{2}$, Ziyun Cheng $\mathbb{D}^{2}$ Liangchao Qu $\mathbb{D},{ }^{2}$ \\ Penghui Su, ${ }^{2}$ Chunliu Sun ${ }^{D}{ }^{2}$ and Wenqi Zhang ${ }^{2}{ }^{2}$
}

${ }^{1}$ PetroChina Exploration \& Production Company, Beijing, China

${ }^{2}$ PetroChina Research Institute of Petroleum Exploration and Development, Beijing, China

Correspondence should be addressed to Yunpeng Hu; huyunpeng1129@petrochina.com.cn

Received 22 January 2021; Revised 31 May 2021; Accepted 3 August 2021; Published 19 August 2021

Academic Editor: Yingfang Zhou

Copyright (@) 2021 Yunpeng Hu et al. This is an open access article distributed under the Creative Commons Attribution License, which permits unrestricted use, distribution, and reproduction in any medium, provided the original work is properly cited.

\begin{abstract}
A bottom water reservoir is universal in all reservoirs in the world. In the exploitation process of the bottom water reservoir, because the reservoir is in complete contact with bottom water, the natural energy supply of the bottom water reservoir is sufficient. At the same time, in the production process, the pressure drop generated by the formation is mainly concentrated near the wellbore, which leads to a short period of waterless oil production, fast water breakthrough, and fast water cut rise, which seriously affects the overall recovery factor and increases the risk of oil filed exploitation. Since the distribution of an interlayer enhances the heterogeneity of the reservoir, it has a prominent impact on the flow of oil and water in the bottom water reservoir. However, people know little about the impact of the interlayer on the bottom water reservoir. In this paper, the mathematical model of two-phase flow in the bottom water reservoir with the interlayer is proposed, and the numerical solution of the model is obtained by a finite element method. The influence of the distribution of the interlayer on the water cut rising law of the bottom water reservoir is analyzed. The results show that the bottom water is blocked by the interlayer and its own gravity and the rising height of the bottom water is limited, so that the interlayer has a significant inhibitory effect on the coning of the bottom water. The closer the interlayer is to the oil-water interface, the faster the water cut will rise; the narrower the interlayer is, the faster the bottom water ridge will advance; when the width of the interlayer is the same as that of the reservoir, the water cone will not appear; the higher the permeability of the interlayer is, the faster the upper body of the water cut will be; when the permeability of the reservoir and the interlayer is over 1000, the influence of the interlayer on the water cut rise is not obvious; the thickness of the interlayer on the water cut rise law has little effect. Finally, through the case analysis, it is proposed that the new horizontal wells should be arranged in the position where the interlayer develops. The findings of this study can help for the better understanding of control laws of the interlayer on the bottom water and providing a crucial theoretical basis for the development of the bottom water reservoir.
\end{abstract}

\section{Introduction}

An interlayer refers to the nonpermeable layer or ultralow permeable layer which is locally developed and discontinuously distributed in the reservoir. It is an important reason for the horizontal and vertical heterogeneity of the reservoir and is mainly controlled by the original sedimentation process and late diagenesis. In the development of a bottom water reservoir with the interlayer, the existence of the interlayer will lead to an unbalanced liquid production profile of horizontal wells, and the interlayer shielding section will produce more fluid and flood easily. Li deduced the water breakthrough prediction formula of the semipermeable barrier bottom water reservoir and made a theoretical discussion on the water cone shape [1]. Zhang and Sun analyzed the influence of interlayer properties on the inflow of the bottom water cone [2]. Based on the numerical simulation method, Zheng et al. analyzed the influence of interlayer permeability, interlayer size, and interlayer location on the development effect of the bottom water reservoir [3]. Zhao et al. used a numerical model to study the influence of permeability, size, and distribution of the interlayer on bottom 


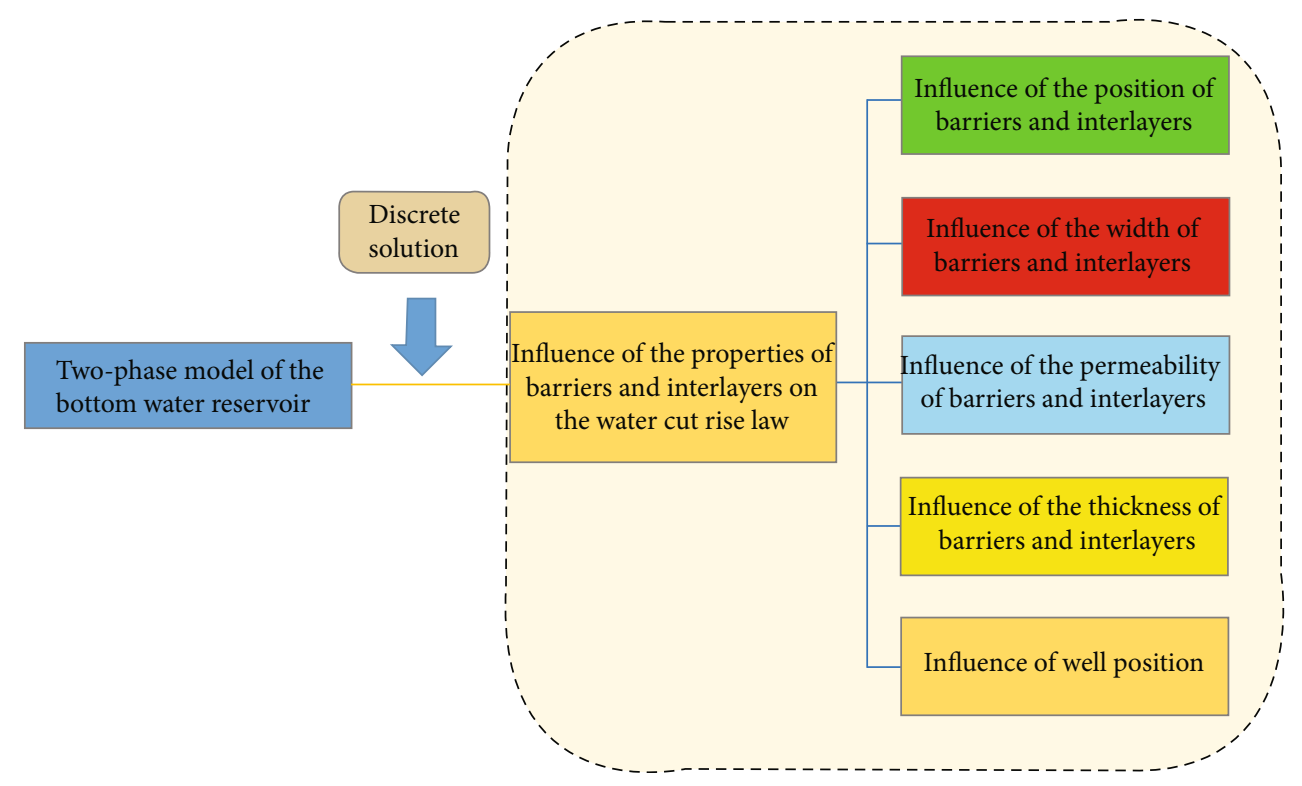

FIGURE 1: Research of numerical simulation of the bottom water reservoir with barriers and interlayers.

water reservoir development [4]. It is considered that the water breakthrough time and productivity of horizontal wells do not increase monotonously with the decrease in interlayer permeability. There is an optimal interval for interlayer permeability, and there is also an optimal interval for interlayer size.

In terms of water cut of the oilfield, there are many factors affecting the increase in the water cut of oilfields, and different types of reservoirs have different water cut rise laws. Therefore, appropriate water cut variation curves shall be selected reasonably according to the physical properties of reservoirs and fluid properties to analyze and predict the change in water cut; then, different countermeasures can be taken in accordance with the objective law of reservoir development, thereby effectively controlling the water cut rise rate, extending the stable production period, and improving the development level of oilfields [5-7]. Wan divided five different types of displacement characteristic curves according to the relationship between recovery percent and water cut, including convex curve, convex and S-shaped transition curve, S-shaped curve, concave and S-shaped transition curve, and concave curve [8]. $\mathrm{Li}$ et al. divided the water cut rise characteristics of horizontal wells into four types such as well opening waterflooded type, rapid waterflooded type, stepped rise type, and climbing type [9]. Wei et al. developed a transient flow model considering the water influx/waterflood. Subsequently, the functions of the production decline-type curves for a vertical well with a water influx/waterflood are derived based on the material balance equation [10]. Liu and Cheng's research shows that the farther the barriers and interlayers from the OWC, the better the horizontal well development effect [11]. Xue et al. analyzed the water cut rise law of horizontal wells under four distribution patterns such as no interlayer, permeable interlayers, small-scope impermeable interlayers, and largescope impermeable interlayers [12]. Wang et al. established five distribution patterns of barriers and interlayers and

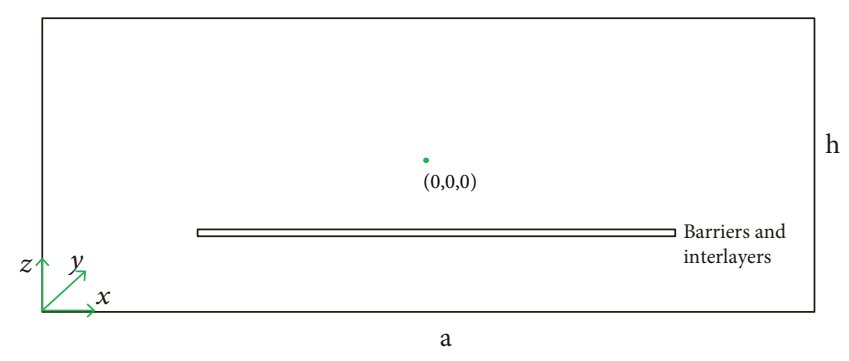

FIgURe 2: Schematic diagram of the profile of the bottom water reservoir with barriers and interlayers.

studied the influence of them on water body migration in bottom water reservoirs [13]. The water cut rise characteristics of horizontal wells have been studied to some extent [14-18].

At present, the research on the influence of the interlayer on the development of the bottom water reservoir mostly adopts the numerical simulation method, but the numerical simulation also has its limitations, mainly for the need to establish a matching geological model and numerical simulation model; the accuracy of the model depends on the level of operation and proficiency, and the workload is huge. Therefore, it is of great theoretical value and practical significance to deduce the effect of the interlayer on the oil-water flow process in theory and establish a mathematical model that can accurately simulate oil-water flow in horizontal wells of the bottom water reservoir. This is also the advantage of our research, which is to better reflect the relationship between the interlayer and the change of water cut by establishing the oil-water two-phase mathematical model of the horizontal well in the bottom water reservoir with the interlayer. However, there will be some errors for specific instances. However, there will be some errors for specific instances. 
TABLE 1: Mechanism model reservoir and fluid parameters.

\begin{tabular}{lccc}
\hline Parameter & Value & Parameter & Value \\
\hline Reservoir width $(\mathrm{m})$ & 150 & Reservoir height $(\mathrm{m})$ & 50 \\
Reservoir length $(\mathrm{m})$ & 400 & Horizontal well center coordinate $(\mathrm{m})$ & $(0,0,0)$ \\
Width of barriers and interlayers $(\mathrm{m})$ & 90 & Thickness of barriers and interlayers $(\mathrm{m})$ & 2 \\
Length of barriers and interlayers $(\mathrm{m})$ & 400 & Center coordinate of barriers and interlayers $(\mathrm{m}) \quad(0,0,-15)$ \\
Included angle of the barriers and interlayers with the $x$-axis & $0^{\circ}$ & Horizontal section length $(\mathrm{m})$ & 200 \\
Reservoir permeability $\left(\mathrm{m}^{2}\right)$ & $1.00 E-13$ & Permeability of barriers and interlayers $\left(\mathrm{m}^{2}\right) \quad 1.00 E-16$ \\
Reservoir porosity & 0.25 & Porosity of barriers and interlayers & 0.0025 \\
Water viscosity $(\mathrm{Pa} \cdot \mathrm{s})$ & 0.0004 & Oil viscosity $(\mathrm{Pa} \cdot \mathrm{s})$ & 0.008 \\
Water density $\left(\mathrm{kg} / \mathrm{m}^{3}\right)$ & 1000 & Oil density $\left(\mathrm{kg} / \mathrm{m}^{3}\right)$ & Water saturation
\end{tabular}

In this paper, firstly a two-phase seepage numerical simulation method for a bottom water reservoir with barriers and interlayers has been established, and then, the influence of the main factors of barriers and interlayers on the water cut rise law has been analyzed; finally, the feasibility countermeasures for the horizontal well layout have been proposed through an example analysis combined with the distribution of barriers and interlayers.

\section{Numerical Reservoir Simulation Research on a Bottom Water Reservoir}

As shown in Figure 1, the main research contents include the establishment of the two-phase flow mathematical model of the bottom water reservoir with the interlayer and the discrete solution by the finite element method and the comprehensive analysis of interlayer position, interlayer size, interlayer thickness, interlayer permeability, the included angle of barriers and interlayers with the $x$-axis, etc. on the water cut rise law.

2.1. Two-Phase Model of the Bottom Water Reservoir. Figure 2 shows the reservoir profile. Assume that the length of the reservoir is $a$, the width is $b$, the height is $h$, the length of the horizontal well is $L$, and the center coordinate of the horizontal well is $(0,0,0)$. By ignoring the capillary force effect, oil-water two-phase seepage flow occurs. Then, the oil-water two-phase control equation is described as follows:

$$
\frac{\partial(\rho \phi)}{\partial t}+\nabla(\rho \vec{v})=0
$$

Motion equation:

$$
\vec{v}=-k\left(s_{\mathrm{w}} \frac{k_{\mathrm{rw}}}{\mu_{\mathrm{w}}}+s_{\mathrm{o}} \frac{k_{\mathrm{ro}}}{\mu_{\mathrm{o}}}\right)(\nabla p+\rho g) .
$$

State equation:

$$
\rho=s_{\mathrm{w}} \rho_{\mathrm{w}}+s_{\mathrm{o}} \rho_{\mathrm{o}} .
$$

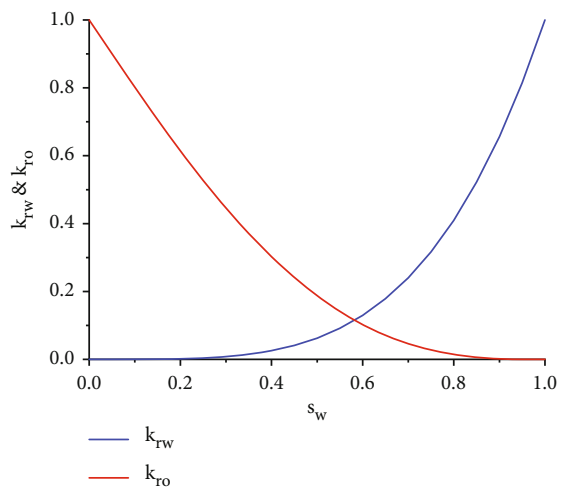

FIGURE 3: Relative permeability curves.

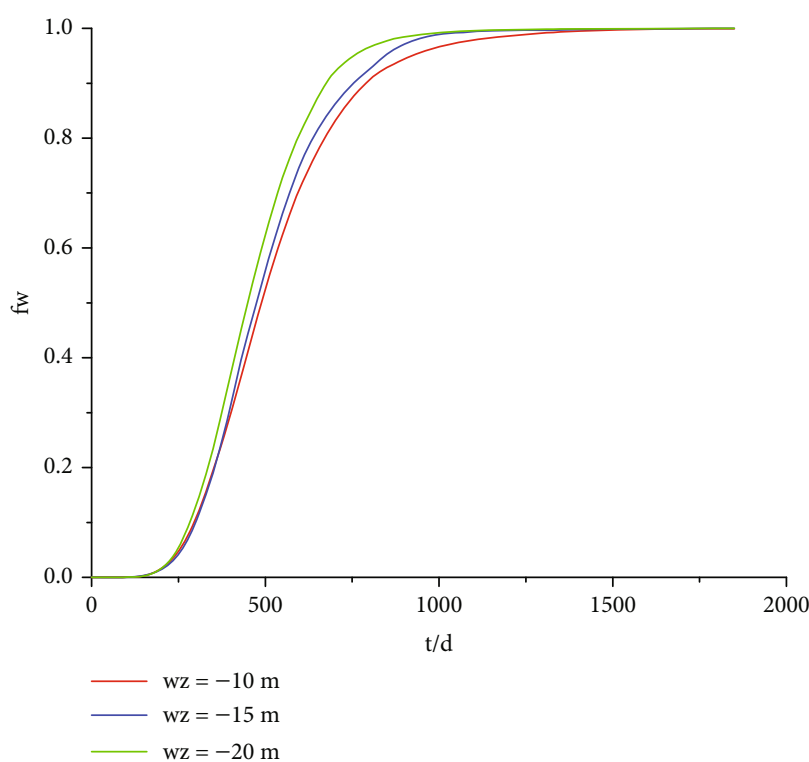

FIgURE 4: Influence of the position coordinates of barriers and interlayers on the water cut.

Auxiliary equation for water saturation and oil saturation:

$$
s_{\mathrm{W}}+s_{\mathrm{o}}=1 \text {. }
$$




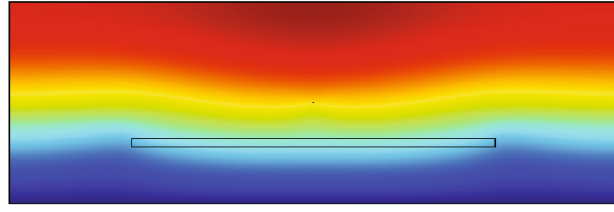

$w Z=-10 m, t=1000 d$

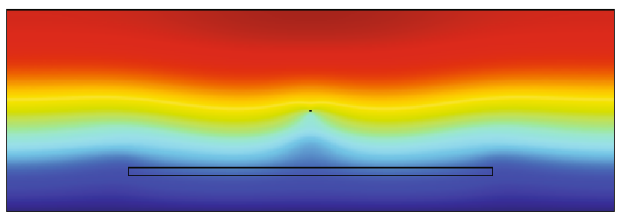

$w Z=-15 m, t=1000 d$

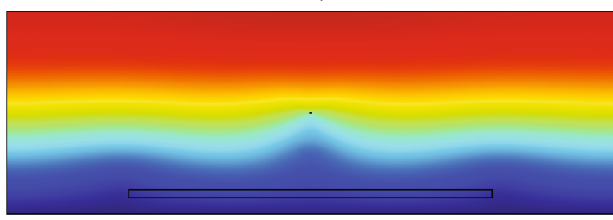

$w z=-20 m, t=1000 d$

FiguRE 5: Water cone diagrams of different positions of barriers and interlayers.

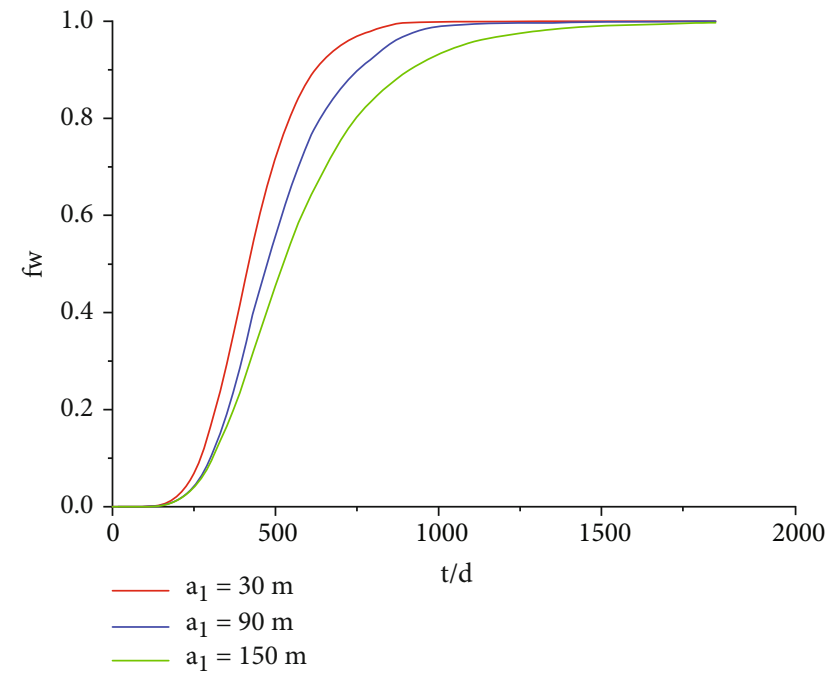

FIGURE 6: Influence of the width $a_{1}$ of barriers and interlayers on the water cut.

Water phase equation:

$$
\frac{\partial\left(\phi \rho_{\mathrm{w}} s_{\mathrm{w}}\right)}{\partial t}+\nabla\left(\rho_{\mathrm{w}} s_{\mathrm{w}} \vec{v}\right)=0
$$

where $\rho_{\mathrm{w}}$ and $\rho_{\mathrm{o}}$ are the water phase density and oil phase density, respectively $\left(\mathrm{g} / \mathrm{m}^{3}\right) ; s_{\mathrm{w}}$ and $s_{\mathrm{o}}$ are the water phase saturation and oil phase saturation, respectively; $\mu_{\mathrm{w}}$ and $\mu_{\mathrm{o}}$ are the water viscosity and oil viscosity, respectively $(\mathrm{Pa} \cdot \mathrm{s})$; $\varphi$ is the porosity; $\mathbf{v}$ is the velocity vector $(\mathrm{m} / \mathrm{s}) ; t$ is the time (s); and $k_{\mathrm{rw}}$ and $k_{\mathrm{ro}}$ are the relative permeability of water and oil, respectively.

Combine equations (1)-(5). The finite element method is used for discrete solution to them. The model reservoir

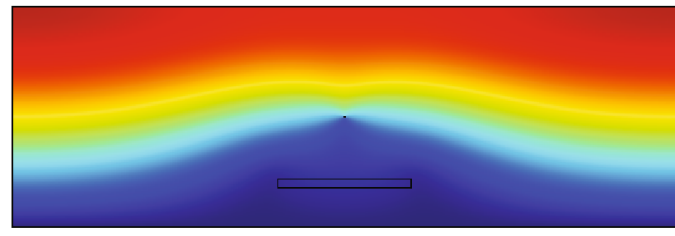

$\mathrm{a}_{1}=30 \mathrm{~m}, \mathrm{t}=1000 \mathrm{~d}$

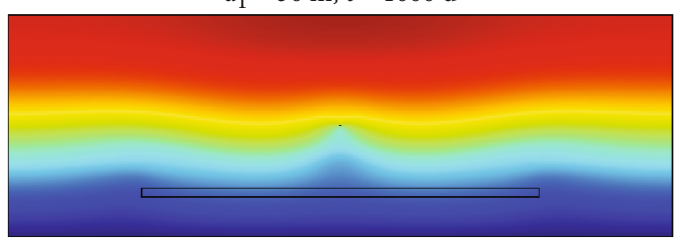

$\mathrm{a}_{1}=90 \mathrm{~m}, \mathrm{t}=1000 \mathrm{~d}$

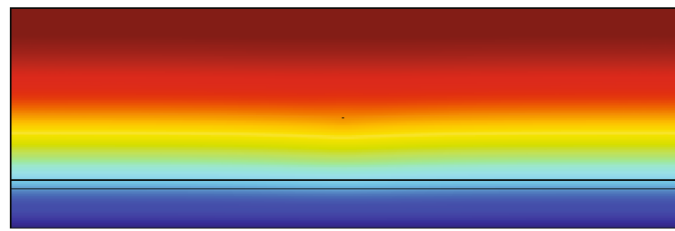

$\mathrm{a}_{1}=150 \mathrm{~m}, \mathrm{t}=1000 \mathrm{~d}$

Figure 7: Water cone diagrams of different widths of barriers and interlayers.

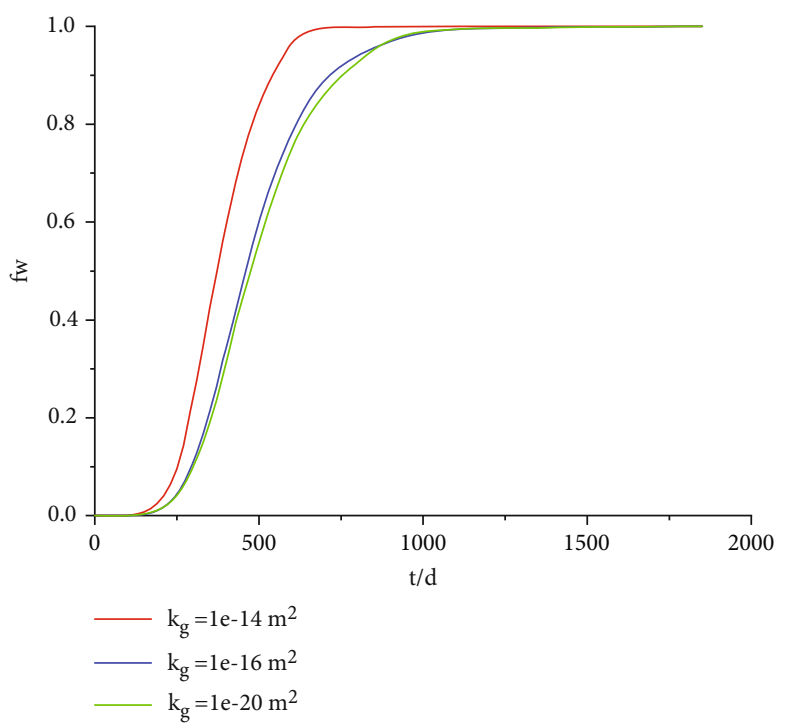

FIGURE 8: Influence of the permeability $k_{g}$ of barriers and interlayers on the water cut.

and fluid parameters are shown in Table 1, and the selected relative permeability curves are shown in Figure 2. This oil well is produced in a constant pressure mode. The initial pressure is set to $12 \mathrm{MPa}$, the bottom hole flowing pressure $10 \mathrm{MPa}$, and the production time is 6 years.

2.2. Influence of the Properties of Barriers and Interlayers on the Water Cut Rise Law. The influence of interlayers on the water cut of the bottom water reservoir has been quantitatively studied in terms of interlayer position, interlayer size, interlayer thickness, interlayer permeability, the included 

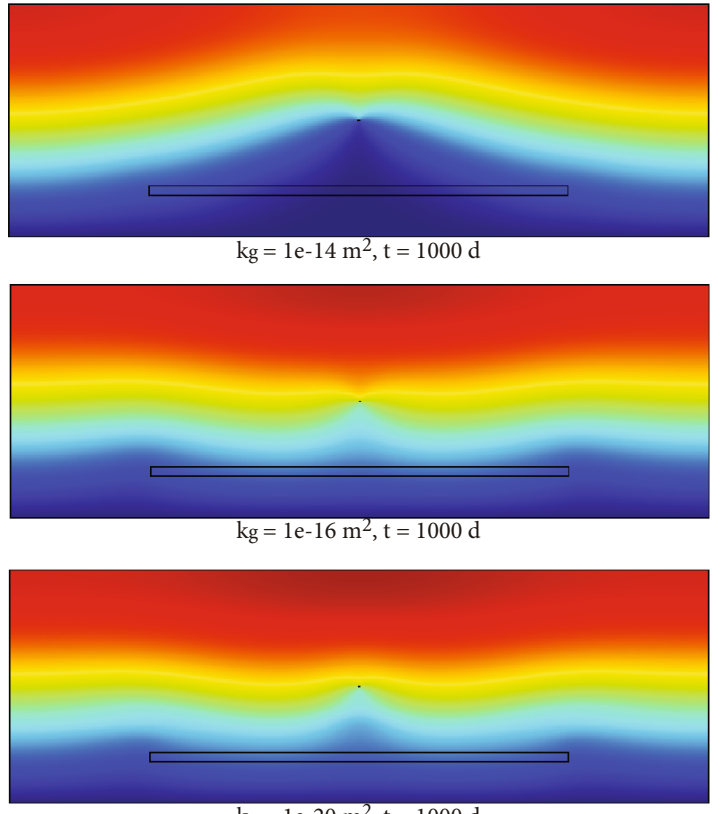

$\mathrm{kg}=1 \mathrm{e}-20 \mathrm{~m}^{2}, \mathrm{t}=1000 \mathrm{~d}$

FIGURE 9: Water cone diagrams of different permeability of barriers and interlayers.

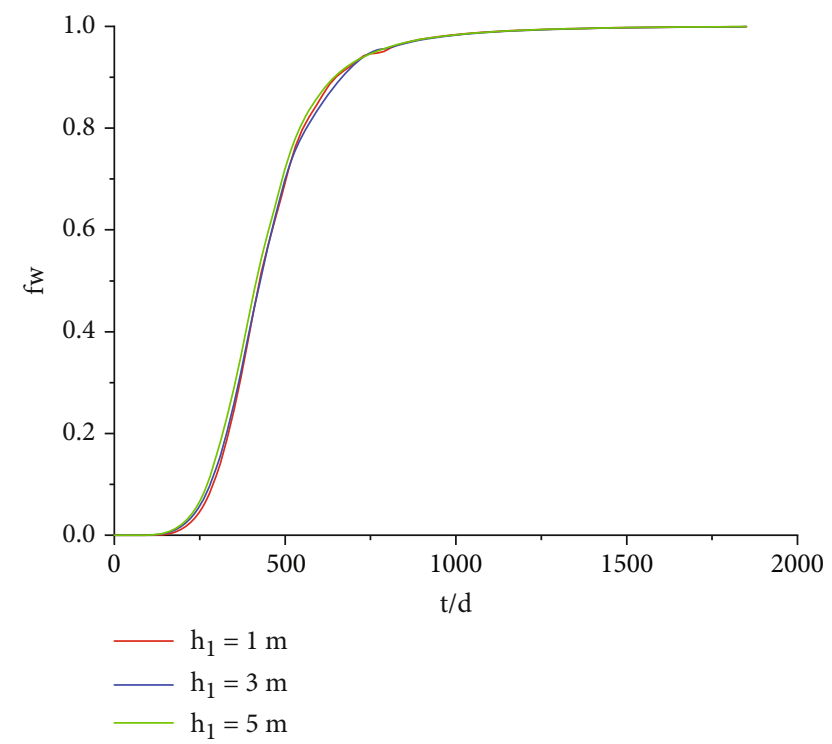

FIGURE 10: Influence of the thickness $h_{1}$ of barriers and interlayers on the water cut.

angle of barriers and interlayers with the $x$-axis, etc. The obtained relative permeability curves are shown in Figure 2, and the basic reservoir parameters are shown in Table 1.

2.2.1. Influence of the Position of Barriers and Interlayers. The center coordinates of barriers and interlayers are set to $(0,0,-10),(0,0,-15)$, and $(0,0,-20)$. Other reservoir parameters and fluid parameters are listed in Table 1. Figure 3 shows the influence of different positions of barriers and interlayers on the water cut rise law. As can be seen in

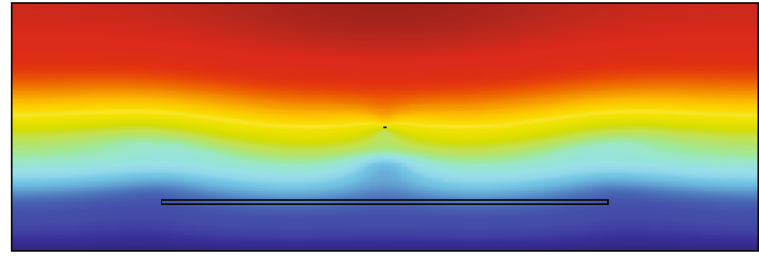

$\mathrm{h}_{1}=1 \mathrm{~m}, \mathrm{t}=1000 \mathrm{~d}$

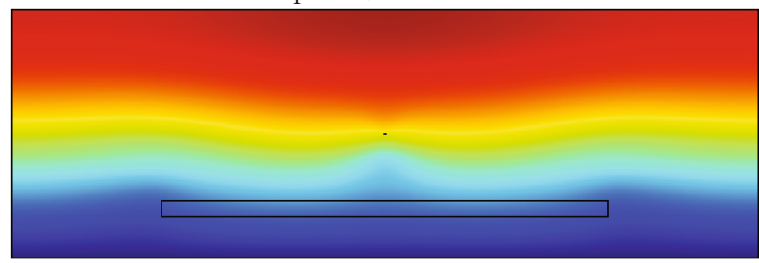

$\mathrm{h}_{1}=3 \mathrm{~m}, \mathrm{t}=1000 \mathrm{~d}$

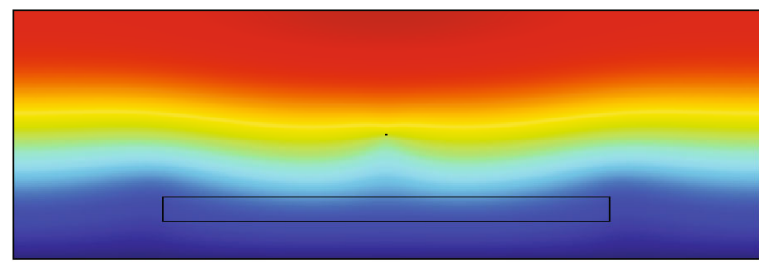

$\mathrm{h}_{1}=5 \mathrm{~m}, \mathrm{t}=1000 \mathrm{~d}$

Figure 11: Water cone diagrams of different permeability of barriers and interlayers.

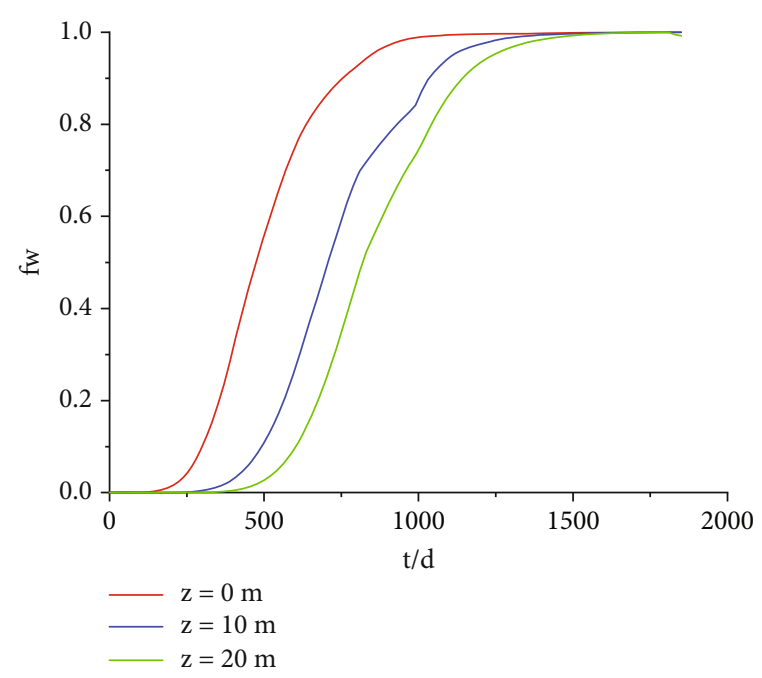

Figure 12: Influence of well position height on the water cut.

Figure 3, different positions of barriers and interlayers have no influence on the water-free oil production period; in addition, the closer the barriers and interlayers are to the OWC, the faster the water cut rises. Figure 4 shows the water cone diagrams of different positions of barriers and interlayers at $t=1000 \mathrm{~d}$. The closer the barriers and interlayers to the OWC, the higher the bottom water cresting rate and the earlier the saturated water in the barriers and interlayers.

2.2.2. Influence of the Width of Barriers and Interlayers. The width of barriers and interlayers is set to $a_{1}=30,90$, and $150 \mathrm{~m}$, respectively. Other reservoir parameters and fluid 
TABLE 2: Statistics of the waterflooded law of the B sand body.

\begin{tabular}{|c|c|c|c|c|c|}
\hline Well no. & Water body & Crude oil viscosity (mPa.s) & Are there interlayers? & Well opening time & Water cut rise pattern \\
\hline $\mathrm{H} 1$ & Edge water & 350 & No & 2014 & Violent waterflooded type \\
\hline $\mathrm{H} 2$ & Edge water & 350 & No & 2009 & Rapid waterflooded type \\
\hline $\mathrm{H} 3$ & Edge water & 350 & Yes & 2004 & Rapid waterflooded type \\
\hline $\mathrm{H} 4$ & Edge water & 350 & Yes & 2005 & Stepped rise type \\
\hline H5 & Edge water & 350 & Yes & 2005 & Rapid waterflooded type \\
\hline H6 & Bottom water & 350 & No & 2015 & Violent waterflooded type \\
\hline $\mathrm{H} 7$ & Edge water & 350 & Yes & 2014 & Violent waterflooded type \\
\hline $\mathrm{H} 8$ & Bottom water & 350 & Yes & 2010 & Rapid waterflooded type \\
\hline H9 & Edge water & 350 & No & 2014 & Violent waterflooded type \\
\hline $\mathrm{H} 10$ & Bottom water & 350 & Yes & 2010 & Stepped rise type \\
\hline H11 & Bottom water & 350 & No & 2013 & Rapid waterflooded type \\
\hline $\mathrm{H} 12$ & Bottom water & 350 & No & 2013 & Rapid waterflooded type \\
\hline $\mathrm{H} 13$ & Bottom water & 350 & No & 2015 & Rapid waterflooded type \\
\hline
\end{tabular}

parameters are listed in Table 1. Figure 5 shows the influence of different positions of barriers and interlayers on the water cut rise law. As can be seen in Figure 5, the smaller the width of the barriers and interlayers, the higher the water cut rise rate.

As can be seen in Figure 6, the smaller the width of the barriers and interlayers, the higher the bottom water cresting rate. When the width of the barriers and interlayers is equal to that of the reservoir, water cones no longer appear.

2.2.3. Influence of the Permeability of Barriers and Interlayers. Figure 7 shows the influence of different permeability of barriers and interlayers on the water cut rise law. The higher the permeability of barriers and interlayers, the higher the water cut rise rate.

When the ratio of the permeability of barriers and interlayers to the reservoir permeability is more than 1000 , the influence of the permeability of barriers and interlayers on the water cut is not remarkable. As can be seen in Figure 8, the higher the permeability of barriers and interlayers, the more serious the bottom water coning. When the ratio of the permeability of barriers and interlayers to the reservoir permeability is more than 1000 , the water cone shape change is not obvious.

2.2.4. Influence of the Thickness of Barriers and Interlayers. Figure 9 shows the influence of different thicknesses of barriers and interlayers on the water cut. As can be seen in the figure, the influence of the thickness of barriers and interlayers on the water cut is small. Barriers and interlayers have a certain inhibitory effect on water cut rise, but they cannot completely seal off the entire reservoir, so the influence of their thickness is small. As can be seen in Figure 10, the variation of the water cone shape at different thicknesses of barriers and interlayers is small.

2.2.5. Influence of the Well Position. Figure 11 shows the influence of different well positions on the water cut curves. As can be seen in the figure, the longer the relative distance between the well and the barriers and interlayers, the lower the water cut and the longer the water-free oil production period. As can be seen in Figure 12, as the relative distance between the well and the barriers and interlayers increases, the phenomenon of bottom water coning is more and more unobvious and even water cones disappear.

\section{Example Analysis}

The B sand body is a typical meandering river sedimentary sand body formed from splicing and superimposition of multistage channel sands and has a thickness of $10 \sim 30 \mathrm{~m}$. The sand body was put into production in 2004, where there are 13 development wells. Bottom water is developed in the high part of the structure of the B sand body, and edge water is developed in the low part of the structure. The natural energy is sufficient, and the reservoir thickness is large. According to the classification statistics of the water cut rise patterns of the single wells in the B sand body, the water cut rise law of the single wells involves 4 violent waterflooded wells, 7 rapid waterflooded wells, and 2 stepped rise type wells (Table 2). The water cut rise types of the single wells are dominated by the rapid waterflooded type, followed by the violent waterflooded type and stepped rise type, without the climbing type (Figure 13).

Figure 14 shows the effective thickness contour map of oil layers in the B sand body. Production of the production wells of the B sand body is mainly related to the distribution of barriers and interlayers in the sand body. The thickness of the interlayers in the B sand body is $0.5 \sim 8.0 \mathrm{~m}$. Their genetic type is mainly the widely distributed flood plain sedimentary mudstones. The development conditions of the interlayers are complex. Due to the repeated cutting action of multistage channels, most of the flood plain mudstones have poor continuity. In general, stable interlayers remain in the middle and east of the B sand body and are mostly developed in the middle and upper parts of the reservoirs. The interlayers in the $\mathrm{H} 10$ well area in the central part are generally thin and have poor blocking ability. The interlayers in the $\mathrm{H} 4$ well area in the east are thick and have an average 


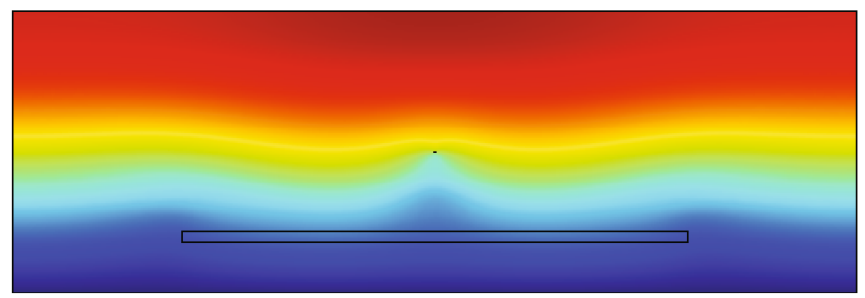

$\mathrm{z}=0 \mathrm{~m}, \mathrm{t}=1000 \mathrm{~d}$

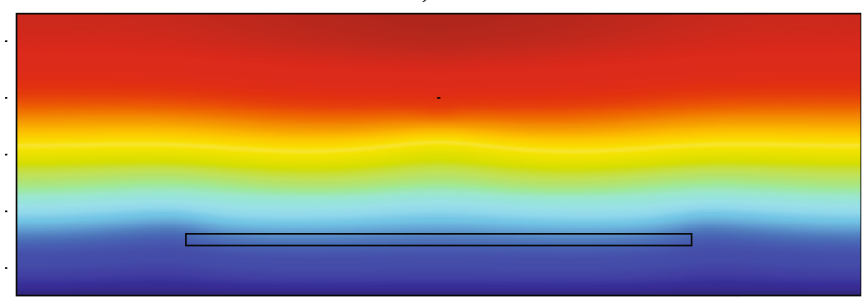

$\mathrm{z}=10 \mathrm{~m}, \mathrm{t}=1000 \mathrm{~d}$

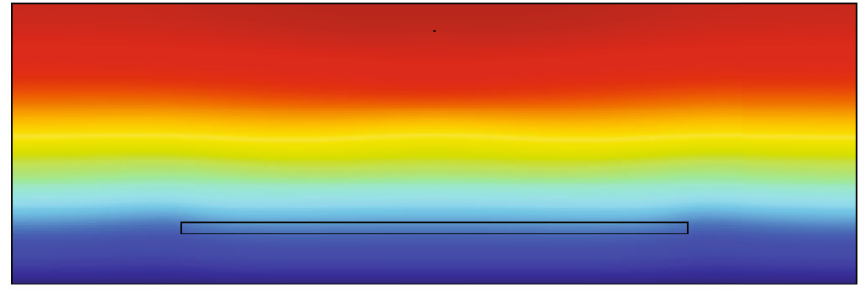

$\mathrm{z}=20 \mathrm{~m}, \mathrm{t}=1000 \mathrm{~d}$

FiguRE 13: Water cone diagrams of different well coordinates.

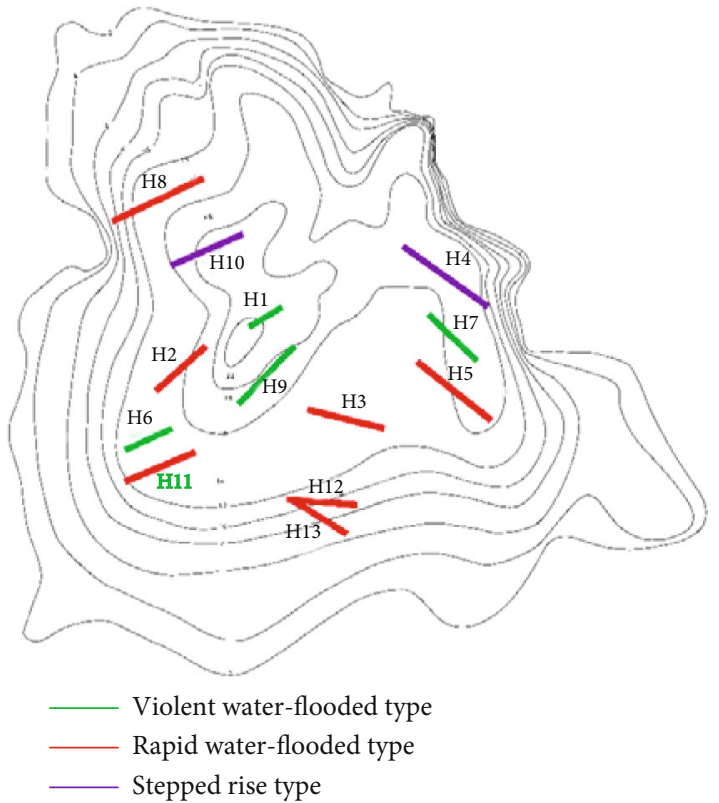

FIgURE 14: Effective thickness contour map of oil layers in the B sand body.

thickness of around $3 \mathrm{~m}$ and strong blocking ability. The 2 production wells with water cut rise characteristics of stepped rise pattern in the sand body are both located in the above areas where barriers and interlayers are developed.
The 4 production wells with water cut rise characteristics of violent waterflooded pattern in the sand body are all adjustment wells in 2014 and 2015. The edge water reservoir in the high part of the structure of the B sand body has been converted into a secondary bottom water reservoir, and the water avoidance height of the adjustment wells has been reduced. After the adjustment wells were put into production, their water cut increased rapidly and they were quickly waterflooded. Late adjustment wells shall be preferentially deployed in the areas with interlayers including $\mathrm{H} 4$ and H10 well areas in order to effectively control the water cut rise rate of new wells and extend their stable production period. The effect of the interlayer can reduce the initial production of horizontal wells, slow down bottom water coning, and improve the development level of the oilfield.

\section{Summary and Conclusion}

(1) A two-phase seepage numerical simulation method for a bottom water reservoir with barriers and interlayers has been established based on the two-phase seepage theory

(2) Interlayers have a certain blocking effect on bottom water. When the distribution scope of interlayers is larger, the water breakthrough time of horizontal wells is longer. As the distance between the interlayer and the OWC increases, that is, as a horizontal well is closer to the interlayer, the water breakthrough time of the horizontal section is extended 
accordingly and the water cut rise rate is lower. If the drilling position of a horizontal well is above barriers and interlayers, its development effect can be improved

(3) According to the analysis of the example and waterflooded law, the feasible countermeasures for the horizontal well layout have been proposed. Based on the distribution of remaining oil in the sand body, the preferred position with the following characteristics for the layout of new wells has been obtained: existence of barriers and interlayers, large water avoidance height, side water reservoir, and moderate fluid production

\section{Nomenclature}

\section{Field Variables}

a: $\quad$ Reservoir width (m)

$b$ : Reservoir length (m)

$a_{1}$ : Width of barriers and interlayers (m)

$b_{1}$ : Length of barriers and interlayers $(\mathrm{m})$

$k$ : $\quad$ Reservoir permeability $\left(\mathrm{m}^{2}\right)$

$k_{g}$ : Permeability of barriers and interlayers $\left(\mathrm{m}^{2}\right)$

$k_{\text {ro }}$ : Relative permeability to oil $\left(\mathrm{m}^{2}\right)$

$k_{\mathrm{rw}}$ : Relative permeability to water $\left(\mathrm{m}^{2}\right)$

$h$ : Reservoir height (m)

$h_{1}$ : Thickness of barriers and interlayers $(\mathrm{m})$

$z$ : $z$-axis value of the horizontal well center coordinate $(\mathrm{m})$

$w z: \quad z$-axis value of the coordinate of barriers and interlayers $(\mathrm{m})$

$v$ : Velocity vector $(\mathrm{m} / \mathrm{s})$

$s_{\mathrm{w}}$ : Water saturation

$s_{\mathrm{o}}$ : Oil saturation

$t$ : $\quad$ Time (s)

\section{Greek Variables}

$\varphi$ : Reservoir porosity

$\mu_{\mathrm{w}}$ : Water viscosity $(\mathrm{Pa} \cdot \mathrm{s})$

$\mu_{\mathrm{o}}$ : Oil viscosity (Pa.s)

$\rho_{\mathrm{w}}$ : Water density $\left(\mathrm{kg} / \mathrm{m}^{3}\right)$

$\rho_{\mathrm{o}}$ : Oil density $\left(\mathrm{kg} / \mathrm{m}^{3}\right)$.

\section{Data Availability}

All data generated or used during the study appearing in the submitted article are available from the corresponding author upon request.

\section{Conflicts of Interest}

The authors declare that there is no conflict of interest regarding the publication of this paper.

\section{References}

[1] L. Chuanliang, "A modified Dupuit formula for critical production rate," Petroleum Expoloration and Development, vol. 20, no. 5, pp. 91-95, 1993.

[2] Z. Xingguo and S. Wei, "A study on the elimination of barrier to bottom water coning," Journal of Northwest University ( Natural Science Edition), vol. 1, no. 2, pp. 149-152, 1999.

[3] Z. Haini, L. Xue, L. Gen, and Z. Meng, "The influencing factors analysis on interlayer controlling bottom water coning in sandstone reservoirs," Xinjiang Geology, vol. 31, no. 5, pp. 44-49, 2013.

[4] G. Zhao, J. Zhou, and X. Liu, "An insight into the development of bottom water reservoirs," Journal of Canadian Petroleum Technology, vol. 45, no. 4, pp. 22-30, 2006.

[5] T. Zhongjing, Z. Longshun, and G. Gao, "Water cut rising rules of the complex fault-block oil reservoirs with the bottom water," Petroleum Geology \& Oilfield Development in Daqing, vol. 36, no. 3, pp. 56-59, 2017.

[6] Z. Wei, Y. Yuedong, and Q. Wangx, "Study on influential factors of water cresting morphology in horizontal well of bottom water reservoirs," Petroleum Geology and Recovery Efficiency, vol. 24, no. 5, pp. 70-77, 2017.

[7] X. Wan, Z. Lu, L. Tingli, L. Ge, X. Liao, and J. Yang, "Research of remain oil distribution and horizontal well development adjustment for heavy oil reservoirs with bottom water," Science Technology and Engineering, vol. 36, pp. 9058-9063, 2010.

[8] J. Wan, "A series of displacement characteristic curve and its application in the prediction performance of waterflooded oil reservoirs(I)," Petroleum Expoloration and Development, vol. 6, pp. 69-77, 1982.

[9] L. Li, D. Luo, and B. Tao, "Water cut rising performance of horizontal wells in thin-bed heavy oil reservoir with edgebottom water in Panyu oilfield," Petroleum Geology and Recovery Efficiency, vol. 23, no. 3, pp. 106-110, 2016.

[10] M. Wei, K. Ren, Y. Duan, Q. Chen, and M. Dejam, "Production decline behavior analysis of a vertical well with a natural water influx/waterflood," Mathematical Problems in Engineering, vol. 2019, Article ID 1683989, 9 pages, 2019.

[11] L. Jia and C. Linsong, "The impact of interlayer to horizontal wells production in bottom water reservoir," Science Technology and Engineering, vol. 13, no. 32, pp. 9662-9665, 2013.

[12] Y. Xue, W. Liang, and G. Chuanlin, "Control effect of interlayers on the migration of oil and water in bottom-water reservoirs," Journal of Xi'an Shiyou University (Natural Science Edition), vol. 26, no. 1, pp. 14-17, 2011.

[13] M. Wang, Z. Guoliang, and F. Min, "Distribution pattern of intercalations and its impact on migration of edge and bottom water in sandy braided-river reservoirs-a case study of Fal structure in P Oilfield, South Sudan," Petroleum Geology and Recovery Efficiency, vol. 24, no. 2, 2017.

[14] L. Guangwei, Z. Daiyu, J. Hanqiao et al., "Water-out performance and pattern of horizontal wells for marine sandstone reservoirs in Tarim Basin, NW China," Petroleum Expoloration and Development, p. 300, 2017.

[15] J. Yin, D. Zhao, and J. Dong, "Numerical simulation on factors affecting flooding mechanism of bottom-water reservoir in horizontal wells," Petroleum Geology and Recovery Efficiency, vol. 19, no. 4, pp. 90-92, 2012.

[16] H. Min, L. Chen, L. Wang, L. Zhang, and J. Chen, "Characteristics and mechanism of water production for fractured vuggy 
carbonate reservoirs, Halahatang oilfield," Journal of Southwest Petroleum University (Science \& Technology Edition), vol. 39, no. 1, pp. 114-123, 2017.

[17] D. Shengguo, Q. Bo, and Y. Jianli, "Main control factors of remaining oil in the oil reservoirs with small gas cap, low amplitude structure and strong bottom water," Petroleum Geology and Recovery Efficiency, vol. 23, no. 1, pp. 129-133, 2016.

[18] D. Shengguo, "Micro-series of strata development technique of scale horizontal well pattern for low amplitude strong bottom water oil reservoir," Special Oil \& Gas Reservoirs, vol. 22, no. 6, p. 118, 2015. 